\title{
The Transport Medicine Society Consensus Guidelines for the Transport of Suspected or Confirmed COVID-19 Patients
}

\author{
Manish Munjal ${ }^{1}$, Syed Moied Ahmed ${ }^{2}$, Rakesh Garg ${ }^{3}$, Samaresh Das ${ }^{4}$, Nilay Chatterjee ${ }^{5}$, Kundan Mittal ${ }^{6}$, Yash Javeri ${ }^{7}$, \\ Subhash Saxena ${ }^{8}$, Sudhir Khunteta ${ }^{9}$
}

\begin{abstract}
Severe acute respiratory syndrome coronavirus 2 (SARS-CoV-2) causes coronavirus disease 2019 (COVID-19) and has been declared as a pandemic. COVID-19 patients may require transport for diagnostic or therapeutic purposes intra- or interhospital or transport from an outside hospital to a healthcare facility. Transport of critically ill or infectious patients is always challenging and involves the integration of various tasks and manpower. The adverse events have been attributed to various factors such as a multidisciplinary team and lack of appropriate communication among team members, absence of equipment, or failure during transport, apart from physiological alteration inherent to the disease of the patient. The transport of COVID-19 patients carries an additional risk of not only the disease itself but also due to the risk of its transmission to the transport team. The human-to-human transmission of the virus can occur via respiratory droplets. So, the person involved in the transport of such patients shall be at risk and warrants appropriate steps for their safety. Appropriate planning by a well-trained transport team is an essence for the safe transport of the suspected or confirmed COVID-19 patients. The Transport Medicine Society guidelines present consensus guidelines for the safe transport of COVID-19 patients.

Disclaimer: These consensus guidelines are applicable for the safe transport of suspected or confirmed COVID-19 adult patients. These recommendations should be used in conjunction with medical management guidelines and advisories related to COVID-19. These recommendations should be adapted to the local policies prevalent at the workplace and also per agreement among the hospitals for transport (agreement between referring and receiving facilities). With the emergence of new scientific evidence, these guidelines may require modification. Keywords: Coronavirus, COVID-19, Critically ill, SARS-CoV-2, Transfer, Transport. Indian Journal of Critical Care Medicine (2020): 10.5005/jp-journals-10071-23584
\end{abstract}

\section{Preamble}

Severe acute respiratory syndrome coronavirus 2 (SARS-CoV-2) is the causative for coronavirus disease 2019 (COVID-19). ${ }^{1,2}$ This disease has recently been seen across the globe and thus declared as a pandemic by the World Health Organization (WHO). During this prevailing pandemic, every hospital will have a significant number of suspected and confirmed patients suffering from COVID-19. The concern is not only about the availability of the transport infrastructure but also about familiarizing staff with the workflow, as the virus is very contagious. The human-to-human transmission of the virus can occur via respiratory droplets directly (through droplets from coughing or sneezing) or indirectly (through contaminated objects or surfaces as fomites). ${ }^{3}$ The persons who are in close contact with the COVID-19 (suspect or confirmed) are most at risk of getting the infection. So, the person involved in the transport of such patients shall be at risk and warrants policy documents for their safety.

A thorough risk-benefit analysis centering on infection control measures like dissemination of contagion and potential benefit to the patient is a prerequisite for any transport. Appropriate planning by a well-trained transport team is an essence for the safe transport of the suspected or confirmed COVID-19 patients. In the absence of established guidelines and protocols, it will be challenging for the accompanying healthcare professionals to contain the spread of COVID-19 infection during transport. Therefore, for transporting these patients, the protocol needs to be formulated and appropriately executed to prevent transmission of disease to the healthcare workers involved. The India-based professional body-Transport Medicine Society-has come
1,9 Department of Critical Care, Transport Medicine Society, India

${ }^{2}$ Department of Anaesthesiology and Critical Care, Jawaharlal Nehru Medical College, Aligarh Muslim University, Aligarh, Uttar Pradesh, India

${ }^{3}$ Department of Onco-Anesthesia and Palliative Medicine, Dr Brairch, All India Institute of Medical Sciences, New Delhi, India

${ }^{4,5}$ Department of Anaesthesia and Critical Care, National Health Service, UK

${ }^{6}$ Department of Paeditrics, Pandit Bhagwat Dayal Sharma Postgraduate Institute of Medical Sciences, Rohtak, Haryana, India

${ }^{7}$ Department of Critical Care, Regency Super Speciality Hospital, Lucknow, Uttar Pradesh, India

${ }^{8}$ Department of Critical Care, Jaipur, Rajasthan, India

Corresponding Author: Syed Moied Ahmed, Department of Anaesthesiology and Critical Care, Jawaharlal Nehru Medical College, Aligarh Muslim University, Aligarh, Uttar Pradesh, India, Phone: +91 9897454739, e-mail: syedmoiedahmed123@gmail.com

How to cite this article: Munjal M, Ahmed SM, Garg R, Das S, Chatterjee N, Mittal K, et al. The Transport Medicine Society Consensus Guidelines for the Transport of Suspected or Confirmed COVID-19 Patients. Indian J Crit Care Med 2020;24(9):763-770.

Source of support: Nil

Conflict of interest: None

forward to propose the guidelines that shall be a useful document for all the stakeholders involved in the transport of COVID-19 patients, such as critical care physicians, anesthesiologists, and emergency physicians.

(c) The Author(s). 2020 Open Access This article is distributed under the terms of the Creative Commons Attribution 4.0 International License (https://creativecommons. org/licenses/by-nc/4.0/), which permits unrestricted use, distribution, and non-commercial reproduction in any medium, provided you give appropriate credit to the original author(s) and the source, provide a link to the Creative Commons license, and indicate if changes were made. The Creative Commons Public Domain Dedication waiver (http://creativecommons.org/publicdomain/zero/1.0/) applies to the data made available in this article, unless otherwise stated. 


\section{Materials and Methods}

Experts having knowledge and experience for patient transport reviewed the literature related to concerns during the transport of suspected or confirmed COVID-19 patients. The literature search was done from search engines including PubMed, Embase, Medline, Ovid, and Google Scholar databases. The manuscripts published in English were retrieved from January 2015 until July 2020 related to the transport of patients. The literature related to concerns for the transport of suspect or confirmed COVID-19 patients were searched from December 2019 till July 2020. The key words included coronavirus; COVID-19; critically ill; SARS-CoV-2; transport; transfer; and ambulance in various combinations. The types of manuscripts included reviews, randomized control trials, observational studies, editorials, advisories, consensus statements document, and guidelines. Other society guidelines were also searched. Additional articles were retrieved by cross-referencing and manual searching of the manuscripts. The searched articles were screened for their suitability to be included in this consensus guideline by the three of the authors. Initial search revealed a total of 374 manuscripts, but of these, we included only 22 manuscripts, as they were relevant for framing of these consensus guidelines. These included advisories from government agencies (two), and guidelines form professional bodies (five). The screened manuscripts were shared with the experts and were discussed for formulating the consensus guidelines for the safe transport of suspect or confirmed COVID-19 patients using web-based meetings and e-mail communication. Since the high-level evidence was lacking in many aspects related to the transport of COVID-19 patients, the existing literature related to the transport of critically ill and/or infectious patients was extrapolated by experts in the context of concerns reported for COVID-19 patients during transport.

\section{Discussion}

Transport of critically ill or infectious patients is always challenging and involves the integration of various tasks and manpower. ${ }^{4}$ This is because of adverse events to the patients that may happen during the transport, as the same level of monitoring and care may not be feasible. The various adverse events related to transport include major physiological perturbations, patient dissatisfaction, prolonged hospital stay due to events during transport, injuries (physical and psychological), and even death. ${ }^{4-11}$ These adverse events have been attributed to various factors such as a multidisciplinary team and lack of appropriate communication among team members, absence of equipment, or failure during transport, apart from physiological alteration inherent to the disease of the patient. ${ }^{7,10,11}$ The additional concern related to COVID19 patient's transport is the risk of viral transmission to the transport team and to other persons during the process. The safety not only of patients but also of the transport team can be ensured by the availability of working equipment, trained transport team members (including training of appropriate use of protective equipment and infection control), and written protocols. 6,7,9,12

The COVID-19 patients may require transport for diagnostic or therapeutic purposes intra- or interhospital or transport from an outside hospital to a healthcare facility (Flowchart 1). ${ }^{12-15}$

\section{Intrahospital Transport}

The management of COVID-19 patients requires a dedicated facility. Transport of these patients in the hospital are required for diagnostic (radiological imaging, bronchoscopy, etc) or therapeutic purposes (surgery). ${ }^{6}$ These patients may be diagnosed and identified at different departments of the hospital and thus requires its transport to the designated area for COVID-19. The transport may also be required from isolation wards to critical care units for COVID-19. All such transport has peculiar concerns and require specific care and precautions. ${ }^{6-8,10,13,15}$

\section{Interhospital Transport}

Interhospital transport will be necessary while escalating from primary to the secondary or tertiary level of care, due to lack of critical care facility in a particular hospital. Transport may also be because of the managing patient at a dedicated COVID-19 facility. ${ }^{6,9}$ The transport of these patients carries specific concerns and needs to be taken care of accordingly. ${ }^{6-8,10,13,15}$

\section{Transport from Outside to Healthcare Facility}

The COVID-19 patients may be diagnosed at home or at times at makeshift quarantine centers. These patients may require transport to the hospital if they require monitoring because of the clinical conditions or for other incidental diagnostic or therapeutic interventions.

\section{Challenges and Risks}

The literature on adverse events related to COVID-19 patient transport and its impact on patient or transport team is scarce. However, the etiopathogenesis of the disease highlights that the adverse outcomes may be much higher, and additional events of infection transmission are possible. ${ }^{6,16-19}$ These challenges and risks may be broadly considered as patient-related, training, technical, and administrative concerns. The patient-related concerns are primarily for their critical illness and concerns for infectivity of the coronavirus. The training of the transport team is also challenging, as team needs to be trained for clinical management concerns and training sessions for various interventions such as tracheal intubation, resuscitation, donning and doffing of PPE, etc. in COVID-19 patients. The updated clinical management requires different sets of equipment and their accessories, and appropriate disinfection methods needs to be arranged for transport. The administrative support is required for better coordination between various health-care facilities and appropriate agreements among organizations for COVID-19 patients

The transport team must provide optimum in-transit care ensuring the safety of patients. Monitoring and maintenance of physiological variables at their desired or targeted levels should be maintained during the transport by a well-trained transport team..$^{19}$ The team needs to be trained for specific concerns related to COVID-19, such as the risk of hypoxemia, hemodynamic instability,thromboembolism, etc. The careful patient selection, transport planning, and equipment preparation results in improved outcomes and some studies have shown up to $91 \%$ of these incidences are preventable. ${ }^{17}$ Dissemination of contagion during transport and introduction of infection to newer facilities/hospitals is a major concern. Disinfection and reuse of vehicle and equipment require special attention. The risk of spread of contagion increases in the ambulance and some other transport vehicles, as they make a closed space.

\section{Overview of Planning Considerations}

The need for patient transport must be assessed, and transport should be limited for medically essential reasons. This is primarily due to the contagious nature of the virus, and the risk of infection 
Flowchart 1: Transporting COVID-19 patient

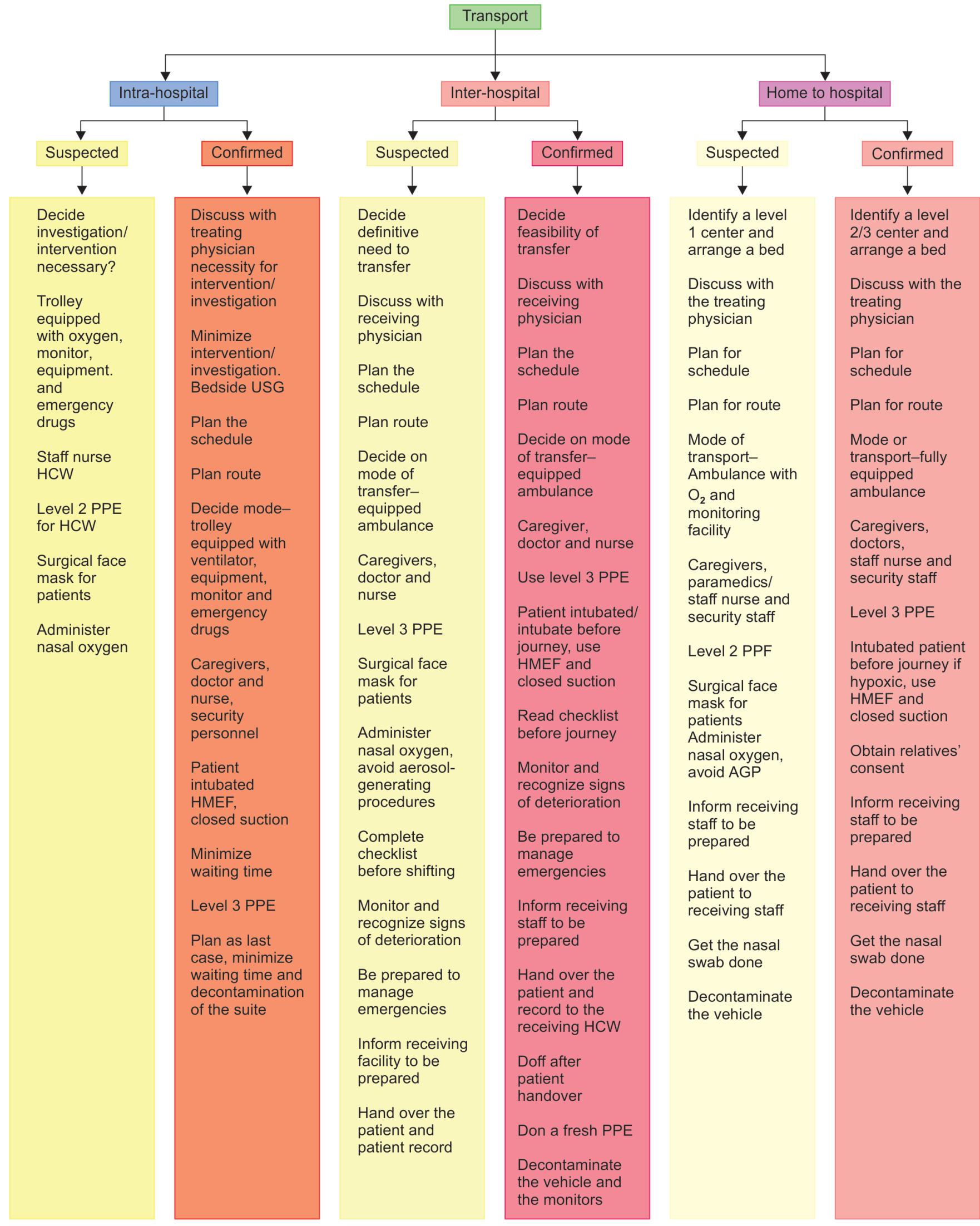


not only to the transport team but also to the other nearby during transport. Unplanned transport of infected cases can lead to nosocomial spread and impasse the efforts of breaking the chains of transmission. The process of transport can be divided into the following stages: ${ }^{16}$

- Need identification-transport for diagnostic/therapeutic intervention or further management

- Direct communication-treating (referring) physician to the referred physician

- Acceptance and scheduling: A physician in agreement to accept the patient and appropriate time for the same.

- Minimum waiting time for diagnostic procedures

- Preparation: Manpower, emergency drugs, monitoring tools, and other equipment

- Referring team

- Transport team

- Receiving team

- Handover: Clinical details (history, examination, imaging, laboratory investigations, etc.)

- Referring critical care unit/treating unit staff to transport team members

- Transport team to accepting team in the referral center

- The safe return of the transport team and equipment to the base facility or hospital

- Disinfection of transport vehicle, path, or vehicle of transport.

- Need for risk assessment and monitoring of transport team personnel.

It is essential to triage and assess the patient's status before planning for shifting. This shall help to assign appropriate manpower and other equipment required during transport. This assessment outcome shall be in conjunction with all the three-team (referring, transport, and receiving teams). We suggest that the transport team can perform initial triage by maintaining atleast 6 feet or 2 meters away and ensuring the patient is wearing a facemask, in addition to inputs from the treating team. In case the patient is being shifted from outside the hospital for its admission to the hospital, initial triage should be done by healthcare worker donned with PPE. Once PPE has been donned, then detailed examination may be performed. Identification and compliance of all these steps using a checklist need to be maintained. An audit of such a checklist along with debriefing after each transport shall be useful for any identification of lacunae or lapse. An immediate corrective step needs to be taken.

\section{Manpower}

Doctors from Critical Care Medicine, Anesthesiology, or Emergency Medicine should lead the transport team as a nodal officer. The nodal officer shall be responsible for all training activities, ensuring appropriate infrastructure for transport and for providing better liaison between stakeholders involved in the transport of the patient. The team members of the transport team shall comprise of the doctor, nursing personnel, technician, multipurpose worker, ambulance driver, and an assistant. It is desirable to keep the fewest transport team personnel to minimize possible exposure to infection.

\section{Capacity Building: Teaching and Training of Manpower Involved in Transport}

The personnel involved should not only be trained appropriately (clinical, equipment related, troubleshooting, etc.) but also needs to be familiar with the transport team and the mode of transport. The team should be well aware of various concerns related to COVID-19. Ambulance staff (technicians as well as drivers) should be trained and oriented about common signs and symptoms of COVID-19 (fever, cough, and difficulty in breathing) and thus able to triage and identify COVID-19 suspects. ${ }^{1,2,4}$ Training is also requisite for infection, prevention, and control practices including the use of PPE. Similarly, the emergency staff of health facilities should be trained in segregation, isolation, and management of COVID19 patients. Simple public health measures like hand hygiene, respiratory etiquette, social distancing, etc. need to be taught and its adherence ensured. Patients and attendants may be provided advisory or poster displayed related to such public health measures.

\section{Communication}

The transportation of COVID-19 patients should be done after communication with concerned teams based on the recommendation of local health agencies. Communication with the teleconference portal including all stakeholders involved in transport shall hasten the decision-making for safe transport. The need for transport should be discussed and appropriately communicated. Prior communication and information shall help in keeping the path clear for patient transport and thus avoid any potential exposure to others. Receiving the unit must be notified of the movement of the patients by departing unit before departure, and an online facility to track the vehicle movement shall be useful for the estimated time of arrival. It must be confirmed by the receiving unit about potential COVID-19 patients coming to their unit. A text or fax is not sufficient, as access to such messages may get delayed to by persons working in COVID-19 facilities. The patient transport to the receiving facility should be direct without the need for multiple channels of reporting and proceeding at a particular hospital. Cross-border transport should be done per local government guidelines.

\section{Personal Protective Equipment}

The transport team members should be trained for appropriately donning the personal protective equipment (PPE). It should be ensured that all components of PPE are available at the facility. The level of PPE required shall be based on the proximity of the transport team members with the patient and also the possible need for any aerosol-generating procedures during the transport (Table 1). Both the emergency medical technicians (EMT) and driver of the ambulance will don PPE while handling, managing, and transporting the COVID identified/suspect patients. Appropriate PPE for patients and their attendants like the use of face mask (triplelayer, or N95, if actively coughing) also needs to be considered.

It is also required to doff PPE at the doorway before exit if patient care was completed in the patient's room. Hand hygiene and new PPE must be donned before leaving the room with the patient. The receiving unit should don PPE before the arrival of the patient to ensure a smooth transition into a predefined area or room. The number of personnel needs to be limited in the patient compartment.

\section{Planning of Transport \\ Baseline Clinical Assessment and Suitability of Transport}

The transport team should collect baseline information of the patient being transported from the treating team. This should include presenting clinical complaints, examination, investigations, 
Table 1: Level of PPE for transport team for COVID-19 patient

\begin{tabular}{|c|c|c|}
\hline Level of PPE & Components of PPE & Indicated for \\
\hline Level 1 & $\begin{array}{l}\text { General precaution } \\
\text { related to infection } \\
\text { control }\end{array}$ & $\begin{array}{l}\text { Choice of PPE based on } \\
\text { proximity of contact }\end{array}$ \\
\hline Level 2 & $\begin{array}{l}\text { Gloves } \\
\text { Water impervious apron } \\
\mathrm{N}-95 \text { mask } \\
\text { Face shield/goggle, (if } \\
\text { risk of splashing) }\end{array}$ & $\begin{array}{l}\text { HCW with spontaneously } \\
\text { breathing patient with } \\
\text { face mask } \\
\text { Driver assisting during } \\
\text { transport }\end{array}$ \\
\hline Level 3 & $\begin{array}{l}\text { Gloves } \\
\text { Water impervious } \\
\text { coverall with head hood } \\
\mathrm{N}-95 \text { mask } \\
\text { Face shield/goggle }\end{array}$ & $\begin{array}{l}\text { HCW mechanically } \\
\text { ventilated patient, } \\
\text { possible need for aerosol- } \\
\text { generating procedures en } \\
\text { route. }\end{array}$ \\
\hline
\end{tabular}

and imaging findings. The information related to treatment and present status should be evaluated. The assessment using "Airway, Breathing, and Circulation (ABC)" is mandatory for documentation and communication. The transport team should discuss with both the referring and the referred facility for this clincial status and need for transport.

\section{Decision and Transport Process}

The need for transport and its final decision should be taken combined by a responsible physician of both the facilities (referring and receiving facility). It is also essential that these physicians should be well versed with concerns in transporting of such patients, and the final decision is based on overall patient status. In case the patient is being received from a non-hospital facility, the receiving hospital shall confirm the eligibility for its admission. However, considering the rapidly changing scenario, which is anticipated during COVID-19 outbreaks, the protocol can be more flexible as per the local/regional arrangements. Because of the highly contagious nature of COVID-19 and rapidly changing physiological variables in critically ill COVID-19 patients, it is suggested that experienced doctors should be engaged in transport when they are undertaking inter-hospital transport, even if it is done under "distant supervision." The risk of transmission of coronavirus remains for aerosol-generating procedures, especially like tracheal intubation, noninvasive ventilation (NIV), manipulation of a BiPAP mask, and manual ventilation before intubation. So, transport decision should be taken accordingly once such concerns are optimally managed. ${ }^{20}$ The use of the checklist shall be useful for the safety of the patient and the transport team (Table 2).

Optimal preparation and stabilization of the COVID-19 patients before transport are of paramount importance to prevent problems and delay. The attempt to optimize with optimal resuscitation is expected before transporting the patient. The endotracheal tube needs to be well secured. Ensure working intravenous access and should be appropriately secured. Ensure that the invasive lines like arterial cannula and central venous catheters are well flushed and secured to prevent its dislodgement during transport. The drugs required during transport especially emergency drugs and life-sustaining drugs like vasopressors and inotropes should be prepared and stocked during the transport. Also, complete documentation needs to accompany. The concerns of fomitebased transmission with various physical documents remain an issue; hence, consideration of electronic documents needs to
Table 2: Ten commands for transport of COVID-19 patient

\begin{tabular}{|c|c|c|c|}
\hline S.No. & Step & Yes/No & Remarks \\
\hline 1 & $\begin{array}{l}\text { Ensure definite need of transport. } \\
\text { Reason identified }\end{array}$ & & \\
\hline 2 & $\begin{array}{l}\text { Ensure stable clinical status of the } \\
\text { patient to be transported }\end{array}$ & & \\
\hline 3 & $\begin{array}{l}\text { Ensure patient/family member } \\
\text { consent }\end{array}$ & & \\
\hline 4 & Decide the mode of transport & & \\
\hline 5 & $\begin{array}{l}\text { Ensure necessary drugs, gadgets/ } \\
\text { equipment required during transport }\end{array}$ & & \\
\hline 6 & $\begin{array}{l}\text { Ensure information at receiving end/ } \\
\text { availability of beds }\end{array}$ & & \\
\hline 7 & $\begin{array}{l}\text { Ensure all the data/record handed } \\
\text { over to the accompanying relative/ } \\
\text { doctor }\end{array}$ & & \\
\hline 8 & $\begin{array}{l}\text { Number of HCWs accompanying/ } \\
\text { required to manage as per patients } \\
\text { status }\end{array}$ & & \\
\hline 9 & The name of the HCWs driver, relative & & \\
\hline 10 & The vehicle number... & & \\
\hline
\end{tabular}

If 'No' for any statement, reason for the same needs to be mentioned in remarks. Any specific concern may also be added

be considered. It is suggested that the use of tablet or similar electronic gadgets for record shall be useful for storing and transport documents and easy access to all without risk of paper contamination. All the teams, particularly the receiving team, should have complete patient information including the estimated time of arrival.

Efforts to be made to minimize the intrahospital transport for investigative interventions. Transport for a computed tomographic (CT) scan may be minimized if bedside ultrasound is acceptable. However, if scanning becomes mandatory, it is advisable to plan it at the end of the day so that the scan center can do terminal cleaning. If intervention (e.g., angioplasty) is planned, the patient must be taken to the respective clinical areas directly. Whenever possible, patients should be placed toward the end of clinical intervention lists. All the teams, particularly the receiving team, should have complete patient information including the estimated time of arrival to the facility. The chief consultant, nodal officer, and administrator should be in the communication loop. A rapid system of communication including the electronic medium of transporting/ sharing patient-related details should be preferred. A complete plan for investigation/procedure and postprocedural transport back to the primary facility should be done.

\section{Tracheal Intubation and Transport}

If a patient is already admitted in ICU, tracheal intubation should preferably take place in a negative pressure room. Intubation should be done using rapid sequence intubation (RSI) technique using a video laryngoscope. ${ }^{21}$ Operator should use PPE with an N-95 mask, and the use of a containment box is preferred. ${ }^{21}$ While connecting to the ventilator, the oxygen flow of closed circuit to be stopped, the endotracheal tube should be occluded using a metallic clamp and thereafter ventilator circuit to be connected. Ventilation should resume after unclamping the endotracheal tube and starting oxygen. High-efficiency particulate absorbing (HEPA) filter should be connected between the endotracheal tube and the breathing 
circuit and at the expiratory port of the ventilator. Intensivist, anesthesiologist, or emergency physician who is responsible for tracheal intubation should take a swab for COVID-19 (if not taken earlier) at the time of tracheal intubation, and ideally should place invasive vascular lines (arterial and central lines) before leaving the room. Auscultation is not advisable, rather consider end-tidal carbon dioxide $\left(\mathrm{EtCO}_{2}\right)$ monitoring as a mandatory tool to confirm correct endotracheal tube placement. Ensure that the endotracheal tube has been well secured before transport.

\section{Emergency Drugs and Equipment}

It is essential not only to have the drugs and equipment during transport, but the appropriate quantity of drugs and working equipment is equally important. The transport team should be aware of these drugs and equipment and their location. Also, additional PPE accessories need to be checked during transport.

The various drugs include sedatives, analgesics, cardiac drugs (vasopressors, inotropes), resuscitation drugs (adrenaline, atropine), and neuromuscular blockers in their appropriate quantity need to be checked before transport of the patient. The fluids and blood products (appropriately labelled) need to be stacked appropriately. The syringes, infusion pumps, and intravenous lines should be ensured.

The various equipment required during transport include transport ventilator, breathing circuit, infusion pumps, cardiac monitors, suction apparatus, defibrillator, heat moisture exchanging filter (HMEF), etc. Equipment used during transport should be checked, charged, and its functionality ensured before transport. A nodal person should ensure the working condition of all the transport equipment, and logbook should be maintained. Resuscitative equipment should also be ensured during transport. This equipment may be stacked in a labeled bag or specifically designed trolley.

\section{Mode of Transport}

The dedicated transport mode needs to be identified for COVID-19 patients. Also, the transport route should be planned to minimize the amount of contact with other personnel (i.e., utilize service elevators, direct routes as much as possible). There should be ambulances identified specifically for transporting COVID-19 suspect patients or those who have developed complications for interhospital transport. ${ }^{3,14}$

The patient's attendant should not be allowed to move along with the patient in the ambulance or during movement on transport trolley. In case, unavoidable, the attendant should be screened for symptoms of COVID-19, wear a surgical mask, and only one may be allowed.

The ambulance should have a compartment for patients separated from driver and glass interface in-between to supervise the patient. In case, if it is clinically required for the healthcare worker to be in the patient compartment, then he should don appropriately. Recirculation of the air for ventilation needs to be avoided and mode adjusted accordingly to maximize fresh air circulation. Also, check the use of the HEPA filter in the airconditioning system of the vehicle. Ensure the use of HMEF in breathing circuits if the patient is on mechanical ventilation. Similarly, for intrahospital transport dedicated transport trolleys, monitoring equipment, crash cart (emergency drugs, and other equipment like airway management) needs to be identified for these patients. Security should be asked to commandeer an elevator to transport the patient. Another staff member wearing PPE for droplet precautions (mask and eye protection) should interact with the environment, e.g., push elevator buttons and open doors and clear the hallway of visitors, patients, and clutter.

\section{Aerosol-generating Procedures (AGP)}

Patients for transport may be receiving management that generates aerosol like oxygenation using high-flow nasal cannula (HFNC), noninvasive ventilation (NIV), or undergo a procedure like tracheal intubation. It is emphasized to ensure that such procedures are undertaken in a controlled environment with all precautions, including appropriate PPE. It is desirable; such procedures should be undertaken before a transport process is initiated.

\section{Components of Safety in Transport}

Safe transfer of patients is essential and includes specific concerns at each point of transport (Table 3). While transporting a suspected/ confirmed COVID-19 patient, the transport team should consider the following:

- Early recognition of the deteriorating patient

- Essential monitoring during transport of COVID-19 patient

- Safety of the healthcare personnel

- Plans to handle any medical emergency arising during transport

- Safety of the bystander

- Post transport decontamination

\section{Early Recognition of the Deteriorating Patient}

The transport team should review the travel history, contact with suspected COVID-19 patients, recent onset of dry cough, running a high temperature, and loss of taste and smell. They should be able to identify a sick patient based on clinical presentation. In case of deterioration, they should consider early tracheal intubation with full PPE, taking necessary precautions before transport. Trigger for tracheal intubation are tachypnea ( $R R \geq 24$ /minute, oxygen saturation $\left(\mathrm{SpO}_{2}<90 \%\right)$ on high-flow rebreathing mask, and Glasgow Coma Score $(\mathrm{GCS})<8$. Following tracheal intubation and placement of invasive lines, the patient is now prepared for further transport to higher referral centers as decided.

\section{Monitoring during Transport of COVID-19 Patient}

A safety checklist should be filled before the transport (this ensures all necessary precautions are in place). Meticulous stabilization, clinical details, and examination ensuring essential monitoring before the transport are of paramount importance. Some of the physiological variables need to be monitored throughout the transport process. In spontaneously breathing patients, basic monitoring tools including electrocardiogram, noninvasive blood pressure, temperature, and pulse oximetry will be adequate. ${ }^{7}$ For patients who are tracheal intubated, additional monitoring of capnography/end-tidal $\mathrm{CO}_{2}$ monitoring $\left(\mathrm{EtCO}_{2}\right)$ is preferable. Patients should be optimally sedated (depending on the clinical condition), and if required neuromuscular blocking agents can be used during the transport to avoid coughing episodes. Alarms (visual and audible) of all the monitors, ventilators, and syringe pumps should be checked and adjusted before the departure. CVP line will help for vasopressor and inotrope administration in case of a hemodynamically unstable patient. Urine output is to be measured while transporting a critically ill patient, mandating placement of a foleys catheter. The ventilation with a closed circuit and HMEF is preferable to manual ventilation. ${ }^{5}$ Also, it is always advisable for the transport team to be in contact with the receiving team at 
Steps required to be adhered by transport team while receiving patient

- Confirm COVID-19 status

- Wear appropriate PPE

- Triage and assess patient condition and decide mode of transport and other monitors and equipment required. Receive all clinical details including treatment. Measure vitals of patient and ensure patient is stable. If patient is being transported on ventilator to a higher center, check ventilatory parameters

- Only one caregiver should be allowed to accompany the patient (while using the prescribed PPE). Ensure availability and provision of adequate triple layered mask and gloves for patient and/or attendant

- Contact the identified health facility for facility preparedness and readiness
Steps required to be adhered by transport team during transport of patient

- Ensure appropriate PPE

- Measure vitals, If required, give supplementary $\mathrm{O}_{2}$ therapy at $5 \mathrm{~L} / \mathrm{min}$ and titrate flow

- If patient is being transported on ventilator to a higher center, follow ventilator management protocols

- Be vigilant especially disconnection from ventilator and monitor the vitals

- Regularly update the status of the patients and your location to the physicians at the receiving end
Steps required to be adhered by transport team while transporting the patient at the receiving unit

- On reaching the receiving hospital, the EMT will hand over the patient and details of medical interventions if any during transport

- After handing over the patient, the PPEs will be taken off as per protocol followed by handwashing. Use Alcohol-based rub /soap water for hand hygiene

- Biomedical waste generated (including PPE) to be disposed off in a biohazard bag regular intervals and update them on the status of the patient and their location.

\section{Safety of Healthcare Personnel}

Transport Medicine Society is committed tothe safety of all healthcare personnel while transporting COVID-19 patients. During this COVID-19 pandemic, all patients with clinical presentations suspected of COVID-19 should be considered as COVID-19 positive, until proven otherwise. All members including drivers should use appropriate PPE during the transport.

If the patient is stable, they should be seated or lying down on a stretcher in the patient compartment. The patient must wear a triple layer surgical mask. If oxygen supplementation is required, it may be delivered using nasal prongs and covered with a triplelayered surgical mask to prevent aerosol formation.

\section{Medical Emergency and Its Management during Transport}

Appropriate optimization and resuscitation before transport remain the key to avoid emergencies during transport. Based on clinical assessment, keep a low threshold for tracheal intubation, if the patient needs transport to another center. Tracheal intubation should follow the principles of experienced personnel wearing PPE, stopping the vehicle, removing the bystanders/family members, and tracheal intubation using rapid sequence intubation (if applicable). If bag-mask ventilation is necessary (e.g., hypoxia, endotracheal tube blockage by secretions) perform it gently using two-hand techniques and always use HEMF attached to the bag. Early tracheal intubation and ventilation using a closed-circuit are desirable.

\section{Safety of the Bystander}

To prevent unnecessary contamination, a dedicated preplanned path should be decided. This path should be decluttered with a minimum of movements of other persons. Under any circumstances, bystanders should not be allowed to accompany the suspected/confirmed COVID-19 patients. In the case of interhospital transport, bystanders should not accompany the patient in the same vehicle. They should be informed over telephone/video conference about the critical status of the patient, and informed consent should be obtained. Considering prevailing precarious situations in many parts of the country, assistance from local police may be needed while transporting such patients to another hospital.

\section{Intra-transport Casualty}

Intra-transport cardiac arrest should be managed per the comprehensive cardiopulmonary life support (CCLS) guidelines for COVID-19 patients. ${ }^{22}$ The availability of mechanical CPR devices will be of immense benefit during transport, as it will increase the efficiency or the outcome of CPR. The patients' attendant and the receiving physician should be updated telephonically on the status of the patient to be prepared appropriately.

\section{Post-transport Decontamination}

The items used during transport and surface needs to be decontaminated after the transport of the patient. Structures such as stretchers, railings, control panels, doors, and work surfaces including ambulance have to be thoroughly cleaned and disinfected. Staff involved with the transport should handover the case to the receiving team at the final destination and doff PPE in their designated bins (all the hospitals should have donningand doffing protocols). In case of intrahospital transport, following handover to the receiving team at the final destination, the transporting team should doff PPEs they used so far and don fresh PPEs before taking all the equipment and monitors to the ambulance in which the patient was brought. In the case of intrahospital transport, the housekeeping team wearing PPE, including a disposable gown, gloves, N-95 mask, and face/eye protection, should perform terminal cleaning of a dedicated route during transport. Terminal cleaning of the ambulance should take place upon arrival back to the primary hospital using triple mopping system technique: ${ }^{3}$ 
- Mopping with plain water or with alcohol-based disinfectant, followed by

- Dry mopping, and then

- Mopping with $0.5 \%$ or $1 \%$ (preferably) freshly prepared hypochlorite solution, and contact time of 10 minutes.

Clean hard, nonporous surfaces in the vehicle-such as seats, armrests, door handles, seat belt buckles, doors, windows and grab handles-should be cleaned with a detergent or soap and water if visibly dirty, before disinfecting. For frequently touched electronic surfaces such as tablets or touch screens, remove visible dirt and then disinfect as per the manufacturer's instructions. If no instruction is available, use wipes or sprays with at least $70 \%$ alcohol. Gloves and N-95 masks are recommended for sanitation staff cleaning the ambulance.

Metals and reusable articles should be sterilized by $70 \%$ alcoholbased sanitizer or as per manufacturer's recommendations.

\section{Monitoring of $\mathrm{HCW}$}

The safety of HCW involved in transport is of paramount importance. HCW involved in transport should self-monitor for signs and symptoms. They should be quarantined and tested if the breach of PPE or exposure has happened. They should be trained as per local health guidelines on reporting and testing when deems necessary.

\section{SUMMARY}

Transport of COVID-19 suspects/confirm carries inherent risk. However, a large number of patients will need transport for varied reasons. The transport should be carried on after a thorough risk-benefit analysis. Communication, transport policies, and safety rules should be stringently followed during the transport process. Availability of PPE and the safety of HCP takes paramount importance.

\section{Authors Contributions Details}

All the authors were involved in concept, literature search, development of the consensus guidelines, manuscript preparation, revision and have checked the final draft. All the authors take complete responsibility for the manuscript.

\section{References}

1. Zhu N, Zhang D, Wang W, Li X, Yang B, Song J, et al. A novel coronavirus from patients with pneumonia in China, 2019. N Eng J Med 2020;382(8):727-733. DOI: 10.1056/NEJMoa2001017.

2. Huang C, Wang Y, Li X, Ren L, Zhao J, Hu Y, et al. Clinical features of patients infected with 2019 novel coronavirus in Wuhan, China. Lancet 2020;395(10223):497-506. DOI: 10.1016/S0140-6736(20) 30183-5.

3. Coronavirus Disease 2019 (COVID-19): Standard Operating Procedure (SOP) for transporting a suspect/confirmed case of COVID-19. Ministry of Health and Family Welfare; Directorate General of Health Services [Emergency Medical Relief]. Available from: https://www.mohfw.gov. in/pdf/StandardOperatingProcedureSOPfortransportingasuspector confirmedcaseofCOVID19.pdf [Last cited on 2020 May 30].

4. Wax RS, Christian MD. Practical recommendations for critical care and anesthesiology teams caring for novel coronavirus (2019-nCoV) patients. Can J Anaesth 2020;67(5):568-576. DOI: 10.1007/s12630-02001591-x.

5. Nakamura T, Fujina $Y$, Uchiyama A, Mashimo T, Nishimura $M$. Intrahospital transport of critically ill patients using ventilator with patient triggering function. Chest 2003;123(1):159-164. DOI: 10.1378/ chest.123.1.159.

6. Liew MF, Siow WT, yao YW, See KC. Safe patient transport for COVID19. Crit Care 2020;24(1):1-3. DOI: 10.1186/s13054-020-2828-4.

7. Gimenez FMP, Camargo WHB, Gomes ACB, Nihei TS, Andrade MWM, Valverde $\mathrm{ML}$, et al. Analysis of adverse events during intrahospital transportation of critically ill patients. Crit Care Research Pract 2017;6847124:1-7.

8. Transport of Patients. Australian College for Emergency Medicine. Available from: https://acem.org.au/Content-Sources/AdvancingEmergency-Medicine/COVID-19/Resources/Clinical-Guidelines/ Transport-of-Patients [Last cited on 2020 May 30].

9. Jia L, Wang H, Gao Y, Liu H, Yu K. High incidence of adverse events during intrahospital transport of critically ill patients and new related risk factors: a prospective, multicenter study in China. Crit Care 2016;20(1):12-16. DOI: 10.1186/s13054-016-1183-y.

10. Bergman LM, Pettersson ME, Chaboyer WP, Carlström ED, Ringdal ML. Safety hazards during intrahospital transport: a prospective observational study. Crit Care Med 2017;45(10):e1043-e1049. DOI: 10.1097/CCM.0000000000002653.

11. Brunsveld-Reinders AH, Arbous MS, Kuiper SG, de Jonge E. A comprehensive method to develop a checklist to increase safety of intra-hospital transport of critically ill patients. Crit Care 2015;19(1):214. DOI: 10.1186/s13054-015-0938-1.

12. COVID-19: guidance for Ambulance Trusts. Available from: https:// www.gov.uk/government/publications/covid-19-guidanceforambulance-trusts. [Last cited on 2020 May 30].

13. Guidance for transport of patients with confirmed or suspected COVID-19 by family members or other non-professionals. Available from: https://www.phila.gov/media/20200329105204/Guide-fortransport-of-patients.pdf [Last cited on 2020 May 30].

14. COVID-2019 Preparedness and Guidance for 911 Call Centers, 911 EMS Response, Decontamination, and Transfer of Highly Suspected or Confirmed COVID-19 Patients. Available from: https://www.nmhealth. org/publication/view/guide/5650/. [Last cited on 2020 May 30].

15. Transportation and Delivery: Plan, Prepare, and Respond - Centers for Disease Control and Prevention. Available from: https://www.cdc. gov/coronavirus/2019-ncov/community/transportation/index.html. [Last cited on 2020 May 30].

16. Bourn S, Wijesingha S, Nordmann G. Transport of critically ill adult patient. BJA Education 2018;18(3):63-68. DOI: 10.1016/j. bjae.2017.11.008.

17. Lovell MA, Mudaliar MY, Klineberg PL. Intra-hospital transport of critically ill patients: complications and difficulties. AnaesthIntensiv Care 2001;29:400-405.

18. Beckmann U, Gillies DM, Berenholtz SM, Wu AW, Pronovost P. Incidents relating to the intra-hospital transport of critically ill patients. An analysis of the reports submitted to the Australian incident monitoring study in intensive care. Intensive Care Med 2004;30(8):1579-1585. DOI: 10.1007/s00134-004-2177-9.

19. Warren J, Fromm JrRE, Orr RA, Rotello LC, Horst HM. American college of critical care medicine. Guidelines for the inter- and intra-hospital transport of critically ill patients. Crit Care Med 2004;32(1):256-262. DOI: 10.1097/01.CCM.0000104917.39204.0A.

20. Schunemann HJ, Khabsa J, Solo K, Khamis AM, Peterson RB, El-Harakeh $A$, et al. Ventilation techniques and riskfor transmission of coronavirus disease including COVID-19. Ann Intern Med 2020. 173. [Ahead of print] 10.7326/M20-2306.

21. Patwa A, Shah A, Garg R, Divatia J, Kundra P, Doctor J, et al. All India difficult airway association (AIDAA) consensus guidelines for airway management in the operating room during the COVID-19 pandemic. Indian J Anaesth 2020;64(14):S107-S115. DOI: 10.4103/ija.IJA_498_20.

22. Singh B, Garg R, Chakrarao SC, Ahmed S, Divatia J, Ramakrishnan $\mathrm{T}$, et al. Indian resuscitation council (IRC) suggested guidelines for comprehensive cardiopulmonary life support (CCLS) for suspected or confirmed coronavirus disease (COVID-19) patient. Indian J Anaesth 2020;64(14):S91-S96. DOI: 10.4103/ija.IJA_481_20. 